\title{
Diagnóstico socioambiental: o meio ambiente percebido por estudantes de uma escola rural de Araras (SP)
}

\author{
Paulo Rogério Lopes ${ }^{1}$ \\ Iara Fonseca de Souza ${ }^{2}$ \\ Marcel Leme ${ }^{3}$ \\ Juliana Andréia Vrba Brandão ${ }^{4}$ \\ Renata Maria Guerreiro Fontoura Costa ${ }^{5}$ \\ Rodolfo Antônio de Figueiredo ${ }^{6}$
}

Resumo: A educação ambiental vem ganhando importância nas últimas décadas como uma temática transversal fundamental a ser trabalhada nas escolas, objetivando um maior entendimento das(os) jovens e cidadãs(ãos) quanto aos problemas socioambientais constituintes da complexa realidade política e social do nosso país. Nesse sentido, realizamos a presente pesquisa em uma escola rural com estudantes da $7^{a}$ e $8^{a}$ série do ensino fundamental a fim de construir um diagnóstico socioambiental, identificar a percepção das(os) mesmas(os) sobre o meio em que vivem e suas perspectivas de futuro e problematizar questões sobre a realidade rural. A metodologia que utilizamos foi a aplicação de questionários semiestruturados e a realização de dinâmicas. O presente trabalho permitiu o desenho de um panorama do meio onde as(os) estudantes vivem e a forma como elas(es) interagem com o ambiente, o que esperamos que contribua para a construção de futuros projetos de educação ambiental para a escola e o município.

Palavras-chave: Educação ambiental popular. Percepção ambiental. Gestão ambiental.

Abstract: Environmental education has gained importance in recent decades as a key horizontal issue to be worked in schools, aiming to provide young people and citizens with a better understanding about the complex socioenvironmental problems as well as the political and social reality of our

1 Doutorando do PPG em Ecologia Aplicada da ESALQ-USP. progeriolopes@hotmail.com

2 Mestranda do PPG em Agroecologia e Desenvolvimento Rural da UFSCar. iarafonsousa@yahoo.com.br

3 Professor da Rede Municipal de Educação de Araras. blacklabel1967@yahoo.com.br

4 Mestranda do PPG em Agroecologia e Desenvolvimento Rural da UFSCar. vrba@uol.com.br

5 Mestranda do PPG em Agroecologia e Desenvolvimento Rural da UFSCar. renatamariaohm@yahoo.com.br

${ }^{6}$ Professor do Centro de Ciências Agrárias da UFSCar. raf@cca.ufscar.br 
country. In this regard, we performed this research in a rural school with 7th and 8th grade students in order to build a socio-environmental diagnosis, to identify their perception about the environment they live in and their prospects for the future, as well as to call into question the rural reality. The methodology we used consisted of semi-structured questionnaires and group activities. This work allowed the overview of the place where the students live and the way they interact with the environment, which we hope can contribute to the construction of future environmental education projects for both the school and the municipality.

Keywords: Popular environmental education. Environmental perception. Environmental management.

\section{Introdução}

A educação ambiental (EA) vem sendo incorporada como uma prática inovadora em diferentes âmbitos. A sua internalização como objeto de políticas públicas de educação e meio ambiente vem ganhando espaço nas últimas décadas, assim como sua incorporação num âmbito mais capilarizado, como mediação educativa, configurando-se em um conjunto de práticas de desenvolvimento social.

Duas diferentes orientações têm sido verificadas dentro do campo da Educação Ambiental: a comportamental e a popular. Na primeira, é valorizado o papel da educação como agente difusor dos conhecimentos sobre o meio ambiente e indutor da mudança dos hábitos e comportamentos considerados predatórios em hábitos e comportamentos tidos como compatíveis com a preservação dos recursos naturais; já a segunda vertente está associada à tradição da educação popular, que compreende o processo educativo como um ato político no sentido amplo, isto é, como prática social de formação da cidadania. Nesse sentido, os destinatários da educação são os sujeitos históricos, inseridos numa conjuntura sociopolítica determinada cuja ação é resultante de um universo de valores construídos social e historicamente (CARVALHO, 2001).

Segundo Carvalho e Grün (2005), "o contexto biologizante das ciências naturais, apoiado numa ecologia científica, muitas vezes leva a uma visão da Educação Ambiental como difusão/explicação de informações corretas e do educador ambiental como um leitor literal do livro da natureza". O discurso da educação ambiental não naturalista é justamente marcado por esse transbordamento teórico-filosófico da questão ambiental em relação às ciências naturais (GAUDIANO, 1999 apud CARVALHO; GRÜN, 2005).

De acordo com Sá (2005), uma das causas da nossa atual crise socioambiental se encontra no ser humano, uma vez que a ação individualista moldada pela lógica industrial capitalista/materialista determina um sujeito que, ao desconhecer as relações que o tornam humano, ignora tudo o que não esteja 
direta e imediatamente vinculado ao seu próprio interesse e bem-estar. Ao correlacionarmos isso com a frase de Leroy (2005, p. 24 apud SATO, 2005), que afirma que "a perda das raízes e da identidade é muito ligada à perda de uma relação com o meio ambiente", nos deparamos com a noção de pertencimento, segundo a qual o sujeito intencionalmente alienado e desvinculado das bases que o sustentam biologicamente, socialmente e espiritualmente não se sente pertencente ao ambiente em que vive, o que resulta numa indiferença, por vezes inconsciente, pela destruição do meio ambiente e também pelas injustiças sociais.

A crença cultural na eficácia milagrosa de um conhecimento puramente instrumental é produzida e reproduz o desenraizamento dos humanos de seu solo biológico e planetário, oculta a complexidade da vida e desliga o humano de seus vínculos intrínsecos com a ordem cósmica (SÁ, 2005).

Por outro lado, através da perspectiva hermenêutica, a produção de conhecimento ocorre pela via compreensiva, em oposição à via explicativa. Nessa perspectiva o sujeito interpreta o mundo à sua volta, assim como se autointerpreta enquanto sujeito constituinte da história, e concomitantemente há a produção de sentidos. Da mesma maneira, a ação e o agir ocorrem simultaneamente a essa interpretação/compreensão: "não há ação possível num vácuo de sentido. Toda ação decorre de certa compreensão/interpretação, de algo que faz sentido" (CARVALHO; GRÜN, 2005). Nessa ótica, reconhece-se que as relações com o meio ambiente são permeadas de sentidos históricoculturais diversos, e não meramente de caráter naturalista/biológico.

Assim, é de extrema importância o vínculo da educação ambiental com a realidade próxima à do sujeito, considerando-se aí suas particularidades, a sazonalidade e o modo de vida. Foi por essa ótica que esta pesquisa se pautou, sendo a área de estudo o meio rural do município de Araras.

Apesar de avanços na mudança de visões, o meio rural ainda é visto como a área atrasada e não desenvolvida, o que resulta em recorrentes preconceitos. Por esse motivo, as(os) estudantes de escolas rurais sentem-se frequentemente envergonhadas(os) de sua situação, almejando muitas vezes ir para as cidades e mudar de vida. Nessa perspectiva, a educação ambiental se configura como uma prática essencial a ser trabalhada no âmbito do ensino rural. De acordo com Zakrzevski (2004), apesar do grande esforço em incorporar a Educação Ambiental nos currículos das escolas, hoje ainda são poucas as intervenções voltadas para a população do campo, sendo esta

uma população marginalizada e esquecida, que vem sofrendo os impactos do modelo de desenvolvimento rural brasileiro gerador de inúmeros problemas econômicos, sociais e ecológicos. Não obstante, a maioria das pesquisas retrata ainda a forma passiva da contemplação ou da compreensão descritiva da situação marginalizada, sem evidenciar uma ação metodológica que possa 
contribuir com as múltiplas teorias tecidas no interior do mosaico da EA.

O presente artigo é resultado de um projeto elaborado no âmbito da ACIEPE Educação Ambiental Popular em Meio Rural, no segundo semestre de 2009, na Universidade Federal de São Carlos, campus de Araras. A ACIEPE é uma inovação pedagógica que tem como objetivo integrar pessoas de diversas origens, sejam elas alunos e alunas da UFSCar, da graduação ou pós-graduação, sejam profissionais residentes na cidade de Araras e região que se interessem pelo tema (FIGUEIREDO, 2010). Portanto, o grupo que se formou para o desenvolvimento deste projeto é heterogêneo, agrupando discentes de pósgraduação, professor da ACIEPE e professor da rede pública do município de Araras, o qual leciona na referida escola onde se deu o desenvolvimento do projeto.

\section{Justificativa e Objetivos}

A escola rural estudada atende cerca de 300 crianças, das quais aproximadamente $80 \%$ moram na zona rural do município de Araras. As primeiras informações provindas da escola indicavam que essas crianças apresentavam baixa autoestima e sentiam-se envergonhadas de estudarem numa escola considerada rural.

O problema que deu origem à investigação foi o fato de que muitas iniciativas de cunho ambiental não tiveram sucesso dentro da escola. Discutindo isso, pensamos ser relevante o desenvolvimento de um diagnóstico socioambiental com os alunos e alunas da $7^{a}$ e $8^{a}$ série para podermos identificar os reais anseios e percepções desses jovens em relação ao meio em que vivem, como também suas perspectivas de futuro.

Dessa forma, o estudo teve por objetivos identificar como os alunos e alunas percebem a realidade em que vivem nos assentamentos e sítios rurais e a maneira como lidam com questões referentes ao saneamento básico, problemas sociais e ambientais.

Acredita-se que a compreensão da forma como as(os) estudantes percebem a realidade de seu entorno é passo importante para o início de um diálogo e trabalho rumo à construção de modelos mais sustentáveis de vida.

\section{Desenvolvimento/Metodologia}

Como metodologia, utilizamos a aplicação de questionários semiestruturados e a realização de dinâmicas (REA; PARKER, 2000, p. 54 e 95). Realizamos três interações diretas com as(os) estudantes na escola, de duas horas cada, em dias espaçados.

As dinâmicas realizadas foram a "teia de apresentações" e a "árvore de problemas" (BUARQUE, 1999, p. 76). A primeira tem por objetivos fazer com que as(os) estudantes se conheçam, demonstrar a importância da participação de 
cada uma(um) no desenvolvimento de ações e ao mesmo tempo averiguar se elas(es) manifestam ou não em suas apresentações sentimentos de orgulho, vergonha, simpatia, antipatia por serem filhas(os) de agricultores familiares. Nessa dinâmica, cada estudante, ao se apresentar, tem em suas mãos um rolo de barbante que é jogado para outro membro participante para que este também se apresente. Ao final, quando todas(os) se apresentaram, o barbante fica todo entrelaçado, revelando um formato de rede. A seguir, todas(os) as(os) estudantes viram-se de costas ao círculo formado e, sob o comando de uma(um) estudante, tentam colocar uma caneta amarrada no centro da rede numa garrafa. Como reflexão dessa dinâmica, procura-se mostrar a importância de cada pessoa na resolução dos problemas e que juntas, respeitando-se mutuamente, são capazes de realizar muitas coisas.

A dinâmica "árvore de problemas" consiste na construção de uma árvore onde os problemas socioambientais e suas causas são apresentados de forma elucidativa. Nessa atividade, pede-se que as (os) estudantes citem diferentes problemas que encontram em nossa sociedade e que também estejam presentes no ambiente onde residem. Os problemas citados são escritos na copa da árvore desenhada na lousa. Após a citação de uma série de problemas, pede-se às(aos) estudantes que falem as raízes (causas) desses problemas. Estas são então escritas nas raízes da árvore, buscando-se assim mostrar as relações entre os problemas e suas causas e, ao mesmo tempo, alertar sobre como tentar resolver esses problemas, indo diretamente às raízes destes.

Os questionários aplicados foram semiestruturados, isto é, as questões sugerem tanto respostas diretas como permitem reflexões e aberturas para informações ainda não determinadas. Foram aplicados dois questionários, um preenchido pelas(os) próprias(os) estudantes e o outro preenchido por grupos formados. O primeiro questionário teve por objetivo conhecer um pouco sobre a percepção socioambiental das(os) estudantes em relação ao local onde residem e estudam. Para tal, foi abordada uma série de questões, como a opinião das(os) estudantes quanto ao local de residência e estudo, as práticas de lazer, quais os problemas socioambientais perceptíveis, entre outras.

O segundo questionário abordou várias questões referentes a saneamento básico, práticas agrícolas e pastoris, características da região onde residem e proteção do meio ambiente. Dessa forma, objetivou-se caracterizar melhor o meio ambiente daquelas(es) estudantes através de suas próprias percepções, o que permitiu identificar quais fatores as(os) preocupavam, as(os) sensibilizavam ou apresentavam diferentes graus de importância.

Ressalta-se que a escolha dos procedimentos metodológicos surgiu no decorrer da pesquisa, com exceção da dinâmica "teia de apresentações" e do primeiro questionário, que foram aplicados no primeiro dia de atividades na escola. Essas duas atividades iniciais forneceram o conhecimento prévio e superficial da realidade a ser trabalhada e assim permitiram que se passasse à reflexão e discussão do que seria importante se desenvolver naquele local. 


\section{Apresentação, Análise dos Dados e Discussão}

Para melhor visualização e compreensão, os dados serão apresentados conforme a ordem cronológica em que foram coletados.

A dinâmica "teia de apresentações" propiciou a apresentação de cada estudante, assim como da equipe proponente da pesquisa. Houve boa compreensão por parte das(os) estudantes da proposta e função da dinâmica e também boa participação, o que permitiu maior aproximação e descontração entre elas(es) e as(os) membros da equipe. Salienta-se que todos os pesquisadores participantes da dinâmica iniciaram as apresentações para que (as)os estudantes pudessem conhecê-las(os) e todas(os) disseram com o que trabalhavam, onde residiam e ainda citaram a sua formação acadêmica, manifestando que cursavam o curso de pós-graduação em Agroecologia e Desenvolvimento Rural (UFSCar Campus de Araras). Propositalmente, um dos pesquisadores, por ser filho de agricultor familiar, enfatizou em sua apresentação sua origem rural e seu forte vínculo com a agricultura, demonstrando orgulho e satisfação pelo fato. Mesmo assim, quando as(os) estudantes se apresentaram, verificou-se que nenhuma(nenhum) delas(es) manifestou que era filha(o) de agricultores ou que residia na zona rural. Tal fato contribuiu para mantermos a hipótese tecida por professoras(es) da escola de que as(os) estudantes possuíam baixa autoestima e, possivelmente, sentiam-se envergonhadas(os) por serem filhas(os) de agricultores, residirem na zona rural e estudarem em um escola rural.

Após essa dinâmica, apresentou-se às(aos) estudantes a razão de nossa presença e quais os objetivos da pesquisa. Em seguida, distribuíram-se os questionários que deveriam ser respondidos individualmente.

As questões do questionário foram divididas em categorias para melhor caracterização das informações coletadas:

Aspectos socioeconômicos e culturais das unidades produtivas das(os) estudantes da zona rural de Araras

A maioria das(os) estudantes entrevistadas(os) nasceu no município de Araras, estado de São Paulo (73\%), sendo os demais nascidos em outros municípios do estado de São Paulo. Noventa e oito por cento dos estudantes residem na zona rural. Desse total, 68\% moram em sítios particulares, onde os pais são, em sua maioria, assalariados e diaristas rurais, e 30\% residem em lotes de assentamentos da reforma agrária. Somente $2 \%$ deles são provenientes da zona urbana, principalmente de bairro periférico, próximo da zona rural.

Verificamos que todas as famílias das(os) estudantes estão envolvidas em atividades agropecuárias (Figura 1). A agricultura praticada por essas famílias se caracteriza por ser tipicamente familiar. Normalmente, as famílias trabalham em suas unidades produtivas e em outras propriedades ou empresas, pois nem sempre a renda oriunda somente da agricultura é suficiente para a sua manutenção financeira. Essa característica do trabalho externo para complemento da renda das famílias é denominada pluriatividade. As famílias 
pluriativas dessas(es) estudantes efetuam atividades diversas: domésticas, rurais, industriais etc.

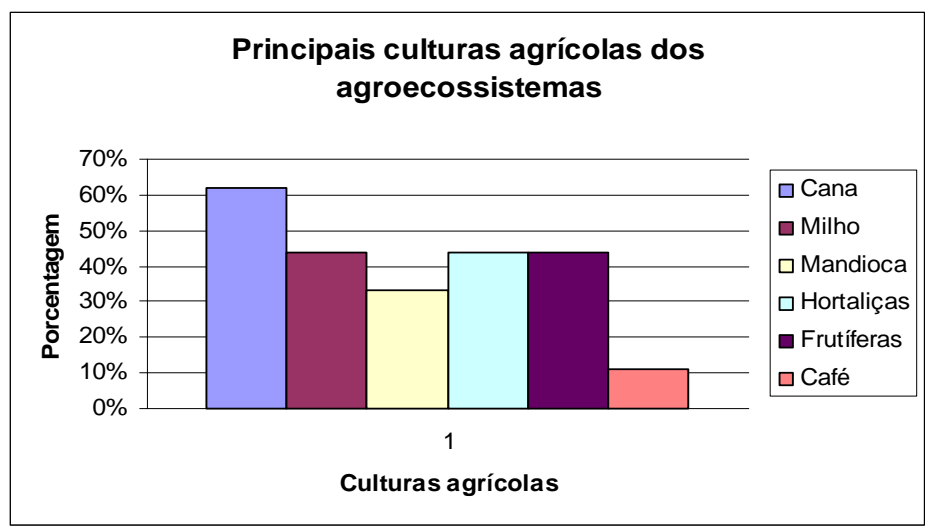

Figura 1. Principais culturas agrícolas plantadas nas unidades produtivas das(os) estudantes.

De acordo com Maluf (2003), a agricultura continua a desempenhar papel central na reprodução econômica e social das famílias rurais no Brasil, embora para a maioria delas sua contribuição menos importante venha sendo a renda monetária obtida com a produção agrícola própria. Segundo o mesmo autor, isso tem ocorrido devido a dois fatores: a tendência de queda dos preços dos produtos agrícolas, que também acarreta a ausência de condições para as famílias aperfeiçoarem o processo produtivo, e a agregação de valor aos produtos agrícolas.

Constatou-se também que 45\% das(os) estudantes trabalham nos períodos vagos para ajudar a família nas unidades produtivas. Pinto (1996) indicou que o trabalho das crianças no meio rural tem por funções a cooperação na atividade econômica das unidades familiares, o aprendizado e a socialização, assim como a função lúdica.

Quanto ao lazer, as principais atividades praticadas pelas(os) estudantes são esportes (55\%), televisão (15\%), conversa com amigas(os) (10\%) e jogos de videogame (8\%) (Figura 2). Pode-se observar que as(os) estudantes não aproveitam o ambiente rural para efetuar atividades de lazer, pois somente 3\% delas(es) afirmaram pescar, nadar ou realizar outras atividades relacionadas ao meio ambiente (Figura 2). Esse fato demonstra a desvalorização do meio rural enquanto ambiente propício também para o divertimento. 


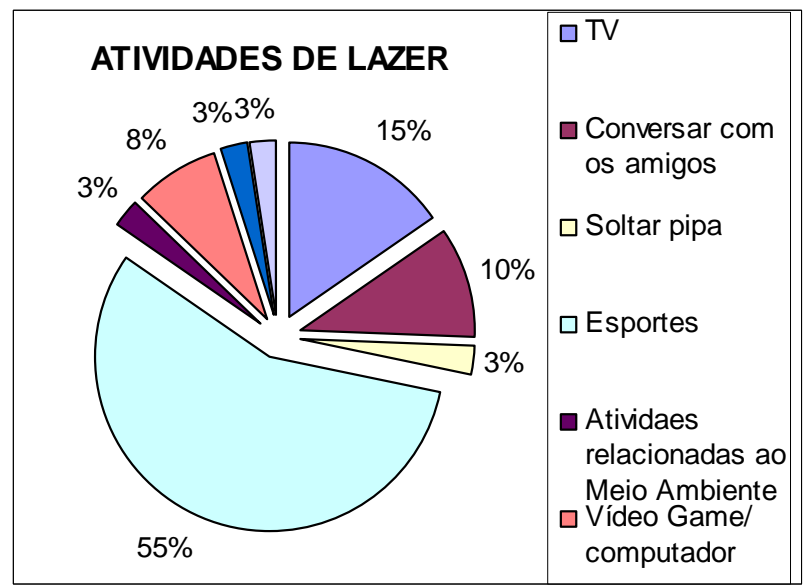

Figura 2. Principais atividades de lazer das(os) estudantes.

Com relação aos anseios futuros, verificou-se que $71 \%$ das(os) estudantes pretendem fazer um curso superior, mas $22 \%$ delas(es) disseram que ainda não refletiram sobre o assunto e 7\% estão indecisas(os) (Figura 3). Devido a essa informação, a equipe optou por discutir juntos com as(os) estudantes, na visita seguinte à escola, questões referentes às diferentes profissões e seus devidos cursos. Procurou-se atentar para as diferenças entre cursos de bacharelado e licenciatura, pós-graduação, cursos técnicos e serviços militares.

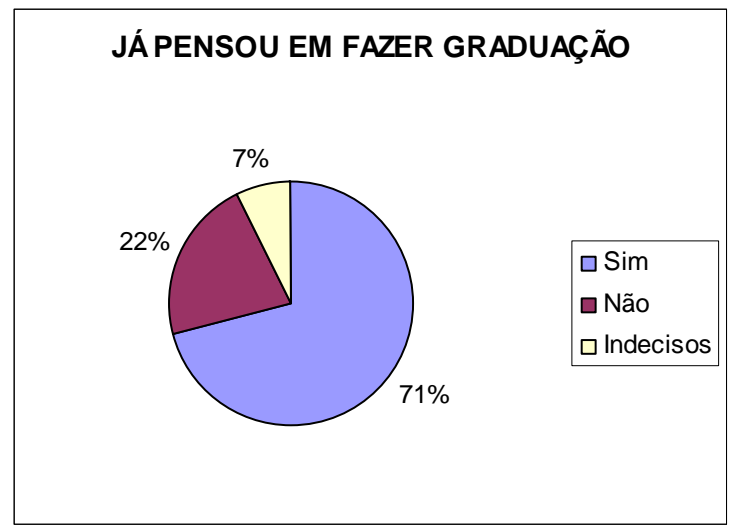

Figura 3. Anseios das(os) estudantes na perspectiva da realização de um curso superior.

Nesse dia, cada membro da equipe apresentou brevemente as atividades pertinentes às suas devidas formações, que no caso são Agronomia, Ecologia e Biologia. Buscou-se apresentar as profissões na forma como elas poderiam se relacionar com o ambiente rural, como, por exemplo, as técnicas de produção agrícola e a importância do conhecimento da interdependência das diferentes formas de vida para o manejo sustentável do agroecossistema. 
Através dessa explanação, as(os) estudantes puderam perceber como o ambiente em que elas(es) vivem são alvo de muita pesquisa e estudo, evidenciando-se assim a importância desses ambientes.

Nesse momento, houve grande interesse das(os) estudantes pelas informações fornecidas e notou-se que esse era um assunto pouco discutido entre elas(es), Esse fato pode estar relacionado à sua baixa autoestima e falta de autoconfiança, que as(os) levam a encarar o ensino superior e/ou técnicos como sonhos distantes de suas realidades.

\section{Percepscão ambiental do meio rural local na ótica das(os) estudantes}

De acordo com a percepção das(os) estudantes, os principais problemas do local onde vivem se constituem na distância das propriedades até a cidade, por elas(es) considerada muito longa, ausência de asfalto na zona rural, presença de muito "mato" no entorno das unidades produtivas, má convivência com vizinhos, lixo e poluição do meio ambiente. Nota-se que os problemas citados demonstram a forte relação com o meio urbano, como a distância da cidade e a ausência de asfalto. Do mesmo modo, revela-se a não aceitação do ambiente rural ao citarem a presença de muito "mato", visto que este é considerado um problema para elas(es). As duas situações refletem o preconceito existente entre as(os) próprias(os) estudantes, que almejam um modo e ambiente de vida iguais aos dos centros urbanos.

No entanto, $40 \%$ das(os) estudantes disseram que não há qualquer problema no meio rural onde vivem. Esse dado demonstra a ausência de autocrítica e conhecimento dos problemas de ordem socioambiental de boa parte das(os) estudantes. São diversos os fatores que contribuem para isso, como, por exemplo, o desconhecimento das consequências de determinadas variáveis relacionadas à saúde ambiental de suas unidades produtivas e de seu entorno e a habituação a situações de risco (SLOVIC, 1987 apud FIGUEIREDO et al., 2004; SLOVIC; FISCHHOFF; LICHTENSTEIN apud FIGUEIREDO et al., 2004).

De acordo com Poltroniéri (1996), cada sociedade responde de maneira diferente aos riscos ambientais, por meio de adaptações e ajustamentos e em função dos níveis ou limiares de conhecimento, de ação e de intolerância, que variam conforme as diferenças de percepções individuais e de grupo.

Estando o risco intimamente associado às dinâmicas socioeconômicas específicas de cada contexto social, a dimensão e a intensidade do mesmo não só [são] percepcionada[s] diferentemente em contextos diversos, como o nível de aceitação, a adesão a medidas de mitigação e a capacidade de intervir na gestão são igualmente divers[o]s. Podemos dizer que, perante situações de risco, cada contexto social desenvolve reações e comportamentos próprios que se encontram dependentes de suas características sociais, culturais, econômicas e políticas (FIGUEIREDO et al., 2004, p. 2). 
Por esse motivo, noutro momento, procurou-se elencar os principais problemas elucidados pelas(os) próprias(os) estudantes, suas causas e possíveis consequências para a saúde e bem-estar de suas e de outras famílias. Para tal, foi aplicada a dinâmica "árvore de problemas", na qual foi possível traçar uma rede de inter-relações dos problemas socioambientais do meio em que vivem e destacar como a ação e o modo de explorar o meio ambiente, isto é, a relação homem-natureza, têm contribuído para a devastação e degradação dos recursos naturais, vitais para a nossa sobrevivência. Entre os principais problemas elencados por uma minoria das(os) estudantes destacou-se a ausência de saneamento básico (esgotamento sanitário), acúmulo de lixo, geração de odores, aparecimento de roedores e insetos causadores de doenças (baratas, moscas, pernilongos), desmatamento, contaminação dos recursos hídricos por agrotóxicos e fertilizantes químicos e desaparecimento da fauna local.

Após a realização dessa dinâmica, que serviu para identificar e mapear diversos problemas socioambientais e levá-los ao conhecimento das(os) próprias(os) estudantes, foi aplicado um novo questionário, que foi respondido em grupo a fim de quantificar e sistematizar os entraves e adversidades do meio ambiente local, além de propiciar maior diálogo e diversidade de reflexões entre as(os) estudantes.

\section{Aspectos ambientais das unidades produtivas dos estudantes da zona rural de Araras}

\section{Residuos sólidos}

Cerca de 54\% das(os) estudantes relataram não ter acesso ao sistema de coleta de lixo municipal. Dessa maneira, 46\% delas(es), periodicamente, queimam os resíduos sólidos e $8 \%$ os enterram ou jogam em valas (buracos no solo). Normalmente, a queima desses resíduos ocorre semanalmente ou quinzenalmente. A disposição inadequada dos resíduos, além de proporcionar mau cheiro e atrair insetos e outros animais transmissores de doenças ao homem, pode ser responsável por contaminações do solo, dos recursos hídricos e do ar e, consequentemente, pela disponibilidade de metais tóxicos ou compostos orgânicos na cadeia alimentar, gerando riscos ecológicos e para a saúde humana (ALMEIDA, 2009).

Essa questão dos resíduos sólidos no meio rural é passível de uma importante reflexão sobre a organização de nossa sociedade, pois, enquanto o meio rural é próximo o suficiente do centro urbano para atender às necessidades de consumo das famílias, não é próximo o suficiente para receber o serviço de coleta de lixo. Isso se agrava ainda mais pelo fato de o meio rural, muitas vezes, apresentar importantes recursos hídricos e fauna e flora específicas.

Apenas cerca de $25 \%$ das(os) estudantes relataram que fazem a separação do lixo frequentemente. Quando foram indagadas(os) sobre a maneira como era realizada essa separação em casa, disseram que separavam as embalagens PET, vidros, alumínios e papéis dos demais resíduos e os entregavam na escola.

Nota-se assim que, além de os resíduos sólidos não serem coletados pela prefeitura do município, não há, por parte do representante de cada família, uma 
ação de separação desse lixo, que poderia ser levado para a escola. Portanto, esse fato corrobora a afirmação de Poltroniéri (1996) sobre as sociedades apresentarem diferentes limiares de ação e intolerância, o que as leva a se posicionar de maneiras distintas diante das situações de risco. Esses limiares estão estreitamente relacionados com a trajetória histórico-cultural dos indivíduos, com o conhecimento das consequências dos riscos, a forma de superação e/ou remediação destes, entre outros fatores (SLOVIC, 1987 apud FIGUEIREDO et al., 2004; SLOVIC et al., 1981 apud FIGUEIREDO et al., 2004).

Observou-se que 78\% das(os) estudantes relataram que não há desperdício de comida, ou melhor, os restos de alimentos são aproveitados para a alimentação dos animais domésticos (gatos, cachorros, galinhas, porcos etc.).

Agua

Com relação à origem da água utilizada nas residências das(os) estudantes, constatou-se que 48\% delas(es) recebem água tratada, 39\% obtêm água de poços artesianos e 13\%, de cisternas (Figura 4). As águas de poços artesianos e principalmente das cisternas, que estão mais próximas da superfície, possuem sérios riscos de contaminação por agrotóxicos, fertilizantes químicos e águas de fossas negras. As(os) estudantes não manifestaram ter conhecimento a respeito desse problema. No entanto, as(os) pesquisadoras(es)/educadoras(es) procuraram explicar como o processo de contaminação da água e do solo pode acontecer. Além disso, discutiu-se com as(os) estudantes as possíveis alternativas para evitar e solucionar esses possíveis entraves de ordem sanitária.

A maioria das residências das(os) estudantes não possui esgotamento sanitário adequado. Cinquenta e nove por cento das unidades produtivas utilizam fossa negra, ou seja, o esgoto é despejado diretamente no solo, sem nenhum tratamento, gerando sérios riscos de contaminação ao meio ambiente local. As(os) estudantes tampouco manifestaram ter conhecimento desse problema. A deficiência em estrutura adequada de esgotamento sanitário poderá acarretar grande número de doenças pelo contato direto da pele com o solo contaminado por larvas de helmintos, provenientes de fezes de portadores de parasitoses, e pela ingestão de alimentos e água contaminados diretamente pelos dejetos (FUNASA, 2006). Segundo Giatti et al. (2004, p. 8): "Essas infecções também podem ocorrer em domínio doméstico, onde a educação sanitária, as noções de higiene e aspectos culturais apresentam relevância na eliminação dessas doenças”. 


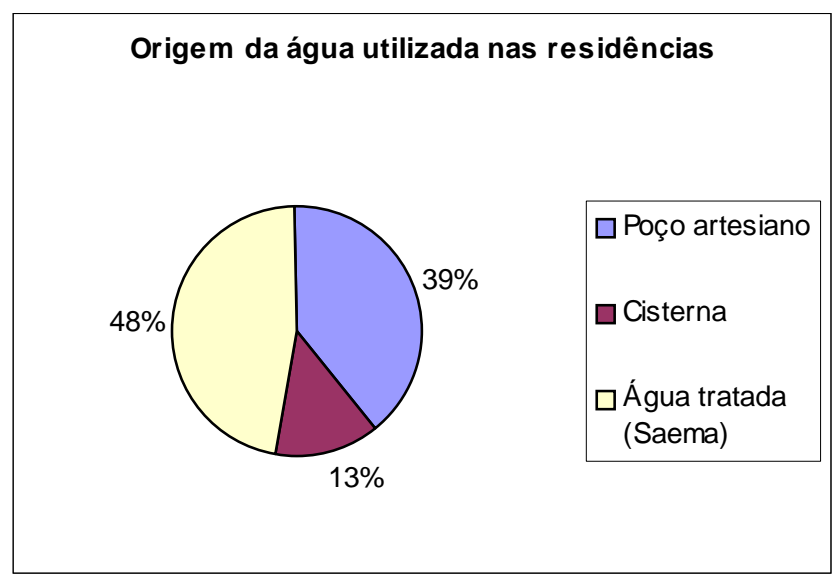

Figura 4. Origem da água utilizada nas residências rurais das(os) estudantes.

Em 30\% das propriedades das(os) estudantes há represas, lagos ou rios. Segundo elas(es), esses recursos hídricos são utilizados para pesca, irrigação de cultivos e para os animais beberem água. Devido à frequente utilização de agroquímicos nas unidades produtivas das(os) estudantes (conforme apresentado no item a seguir) e nas fazendas que cercam as pequenas propriedades, possivelmente essas águas apresentam substâncias indesejáveis e tóxicas em sua constituição, fato que necessita de averiguação.

\section{Produção Agrícola}

As principais culturas agrícolas cultivadas pelos familiares das(os) estudantes são cana-de-açúcar $(60 \%)$, milho (44\%), frutíferas (44\%), hortaliças $(44 \%)$, mandioca (33\%) e café (10\%) (Figura 1). A criação de animais está presente em $70 \%$ dos agroecossistemas. Criam-se, principalmente, aves, suínos, bovinos e ovinos.

Em relação à forma de manejo da produção agrícola, 70\% das unidades produtivas das famílias das(os) estudantes entrevistadas(os) utilizam adubos químicos e agrotóxicos. O elevado índice de unidades produtivas que possuem monoculturas, a queimada (Figura 5) e a utilização de agrotóxicos evidenciam o baixo grau de sustentabilidade das propriedades. Além disso, os familiares das(os) estudantes e muitos delas(es), que colaboram nas atividades agrícolas, correm sérios riscos de contaminação durante a aplicação dos agroquímicos. 


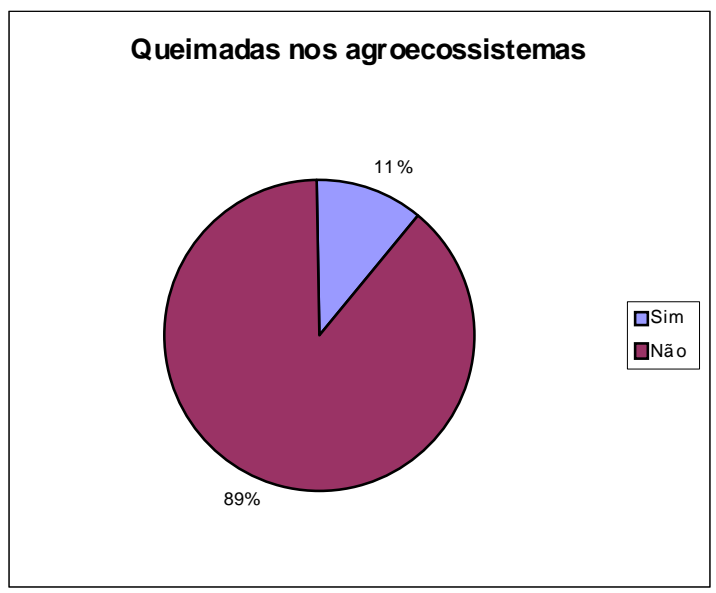

Figura 5. Utilização de queimadas nos agroecossistemas das(os) estudantes.

O rompimento com os processos de resiliência e autossuficiência dos agroecossistemas diversificados, devido à simplificação do ambiente agrícola, tornou as intervenções com agroquímicos necessárias, comprometendo ainda mais as relações ecológicas. De acordo com Gliessman (2005), o sucesso e o impulso da produção de alimentos no último século deveram-se principalmente a avanços científicos e inovações tecnológicas. No entanto, segundo Gliessman (2001), diversos danos ambientais foram causados pela agricultura industrial, tais como: diminuição da fertilidade dos solos, perda de matéria orgânica, lixiviação de nutrientes, degradação e aumento da erosão dos solos, contaminação e esgotamento de fontes hídricas, aumento de pragas e doenças, contaminação de ambientes agrícolas e ecossistemas naturais, danos à saúde de agricultores e assalariados agrícolas, destruição de insetos e micro-organismos benéficos, diminuição drástica da biodiversidade regional e desequilíbrios no ciclo global de nitrogênio, com consequente agravamento dos problemas na camada de ozônio.

Verificou-se também que 56\% das famílias das(os) estudantes necessitam comprar hortaliças e outros itens básicos à alimentação, o que contraria a noção de potencialidade que a agricultura familiar exerce sobre a segurança e soberania alimentar das famílias.

O processo de modernização agrícola já citado gerou uma série de consequências desastrosas nos aspectos ecológicos, econômicos e sociais. Esse processo ocasionou o que foi denominado crise de desenvolvimento. As inovações tecnológicas não se tornaram disponíveis aos agricultores pobres nem se adequaram às suas condições agroecológicas e socioeconômicas. Somam-se ainda os problemas no âmbito da saúde pública, ocasionados pela aplicação de insumos químicos (SOARES; PORTO, 2003).

\section{Fauna e flora}

Apesar da pressão que o ser humano vem exercendo sobre os recursos naturais, $89 \%$ das(os) estudantes disseram que visualizam com frequência alguns 
animais silvestres nativos da região nas unidades produtivas ou no seu entorno (Figura 6). No entanto, $42 \%$ das(os) estudantes notaram que a presença de alguns desses animais nos agroecossistemas tem diminuído nos últimos anos (Figura 7). Tal fato possivelmente está associado ao desmatamento dos poucos fragmentos de matas que abrigam a fauna local e a outras formas de impacto e degradação do meio ambiente (queimadas, poluição, contaminação e expansão da agropecuária), bem como à perpetuação de uma agricultura simplificada. Apesar de a biodiversidade das florestas tropicais ser enaltecida como essencial ao funcionamento dos agroecossistemas, devido à sua potencialidade de uso sustentável e manutenção do equilíbrio dinâmico entre as populações dos seres vivos nos ecossistemas, poucos agricultores conhecem a importância dessa biodiversidade funcional em virtude, principalmente, dessa industrialização da prática agrícola e da desvalorização, por décadas, das práticas agrícolas tradicionais. Portanto, medidas educativas e políticas públicas poderão favorecer a conscientização da população rural a respeito do "valor" intrínseco da biodiversidade e de sua funcionalidade nos sistemas produtivos agrícolas. Segundo Kageyama (2008), biodiversidade e equilíbrio parecem estar associados e se completando nesses ecossistemas tropicais ricos em espécies.

De acordo com 66\% das(os) estudantes, apesar da ausência de hábitats adequados para a manutenção da vida silvestre, ainda existem alguns fragmentos de mata nativa na região onde vivem. Elas(es) também disseram que os animais que mais sofreram pressão humana (caça, destruição de hábitats) foram os tatus, capivaras, pacas, jacarés, pombas, lagartos, rãs e onças.

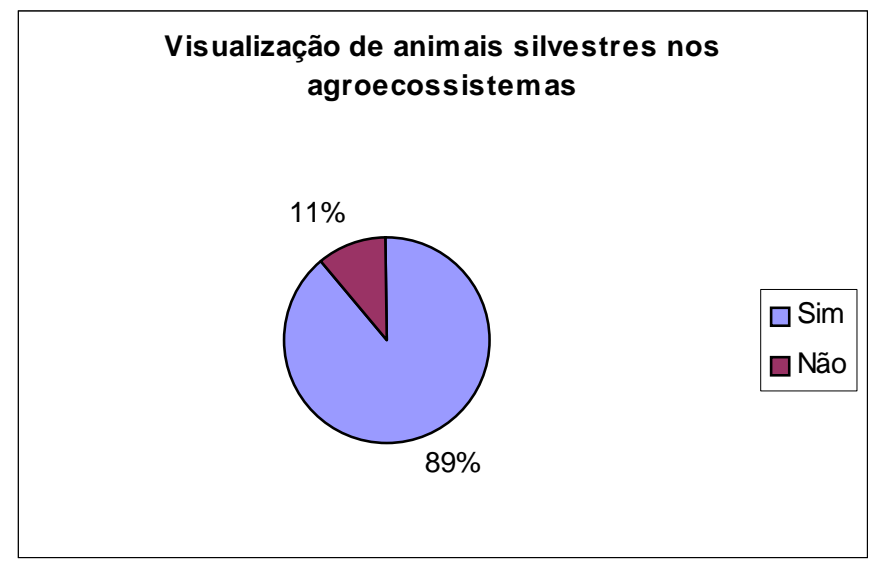

Figura 6. Visualização de animais silvestres nas unidades produtivas e entorno. 


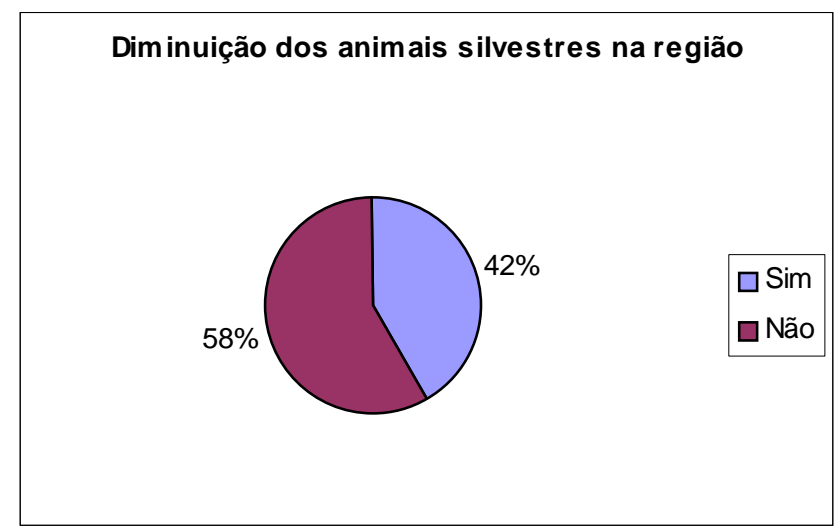

Figura 7. Diminuição da fauna silvestre na região de habitação das(os) estudantes.

Apesar desses dados, 63\% das(os) estudantes disseram que suas famílias se preocupam com o meio ambiente (Figura 8), porém, quando foram indagadas(os) sobre qual seria o tipo de preocupação que a família possuía, a maioria não soube dizer.

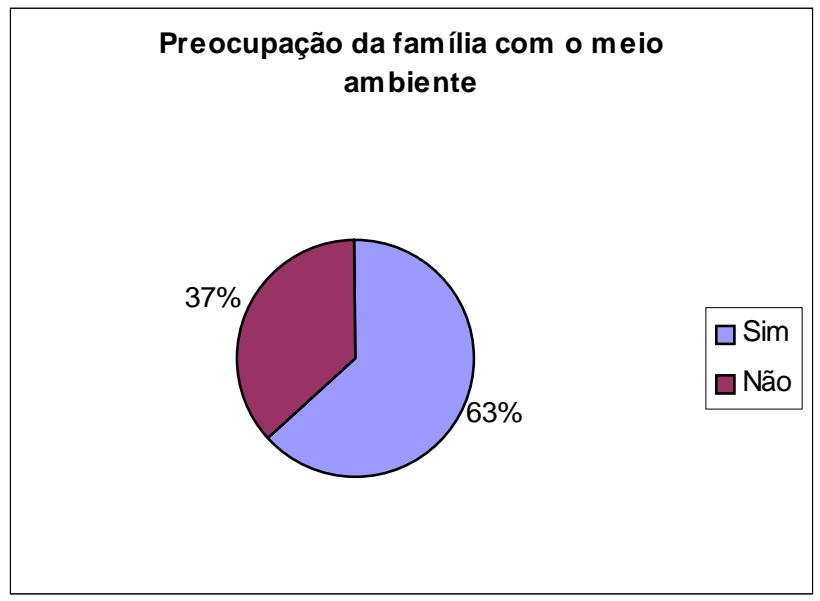

Figura 8. Preocupação das famílias das(os) estudantes com o meio ambiente.

Sobre esse fato, pode-se afirmar que há atualmente um grande desconhecimento das consequências das ações humanas para o meio ambiente. Normalmente, o reconhecimento de ações predatórias recai sobre fatos facilmente perceptíveis, como a caça, o desmatamento, as queimadas etc. No entanto, dificilmente atos como o elevado consumismo, a produção de lixo e a queima de combustíveis fósseis são considerados como prejudiciais ao ambiente, pois não apresentam de imediato suas consequências. Dessa forma, faz-se necessário um maior aprofundamento das relações estabelecidas entre as atitudes cotidianas e suas consequências para a natureza. 


\section{Considerações finais}

O presente trabalho permitiu o desenho de um panorama do meio onde as(os) estudantes de uma escola rural de Araras vivem e a forma como interagem com o ambiente e o percebem. Pode-se concluir que, devido às diversas pressões e preconceitos pelos quais o meio rural já passou, as(os) estudantes apresentam um fraco vínculo com as questões ambientais e com o modo de vida rural.

Portanto, com base no panorama diagnosticado, acredita-se que esta pesquisa contribui para a efetividade de futuras ações extensionistas e de gestão ambiental no meio rural do município. Também se espera que os dados levantados possam contribuir para a construção de um projeto pedagógico que inclua a educação ambiental nas escolas rurais.

\section{Agradecimentos}

As(os) autoras(es) agradecem à diretora da escola rural, que autorizou a realização deste estudo, à ProEx/UFSCar pelo apoio e a três revisores anônimos que muito contribuíram para o aprimoramento de uma versão anterior deste artigo.

\section{Referências}

ALMEIDA, T. L. de. Implicações ambientais dos processos de atenuação de lixiviado em locais de disposição de resíduos sólidos urbanos. 2009. 200 f. Tese (Doutorado em Hidráulica e Saneamento) - Escola de Engenharia de São Carlos, Universidade de São Paulo, São Carlos, 2009.

BUARQUE, S. Metodologia de planejamento do desenvolvimento local e municipal sustentável. Brasília: INCRA/IICA, 1999.

CARVALHO, I. C. de M. Qual educação ambiental? Elementos para um debate sobre educação ambiental e extensão rural. Agroecologia e Desenvolvimento Rural Sustentável, Porto Alegre, v. 2, n. 2, p. 43-51, 2001.

CARVALHO, I. C. de M.; GRÜN, M. Hermenêutica e educação ambiental: o educador como intérprete. In: FERRARO JÚNIOR, L. A. (Org.). Encontros e caminhos: formação de educadoras(es) ambientais e coletivos educadores. Brasília: MMA/Diretoria de Educação Ambiental, 2005. p. 175-187.

FIGUEIREDO, R. A. Educação ambiental popular rural: uma experiência de integração entre ensino, pesquisa e extensão no campus de Araras da Universidade Federal de São Carlos - SP. CCNExt, v. 1, n. 1., p. 57-65, 2010.

FIGUEIREDO, E.; VALENTE, S.; COELHO, C.; PINHO, L. Conviver com o risco: A importância da incorporação da percepção social nos mecanismos de gestão do risco de cheia no concelho de Águeda. In: CONGRESSO LUSO-AFRO-BRASILEIRO DE CIÊNCIAS SOCIAIS, 8., 2004, Coimbra. Anais... Coimbra: Universidade de Coimbra, 2004. 
FUNDAÇÃO NACIONAL DE SAÚDE (FUNASA). Manual de saneamento. 3. ed. rev. Brasília: 2004. 408 p.

GIATTI, L. L. et al. Condições de saneamento básico em Iporanga, estado de São Paulo. Revista Saúde Pública, v. 38, n. 4, p. 571-577, 2004.

GLIESSMAN, S. R. Agroecologia: processos ecológicos em agricultura sustentável. 3. ed. Porto Alegre: UFRGS, 2005. 653 p.

KAGEYAMA, P. Y. Biodiversidade como ferramenta em agroecossistemas. In: CONGRESSO NACIONAL DE BOTÂNICA, 59., 2008, Natal. Anais... Natal: UFRN, 2008.

MALUF, R. S. Multifuncionalidade da agricultura na realidade rural brasileira. In: CARnEIRO, M. J.; MALUf, R. S. (Org.). Para além da produção: Multifuncionalidade e agricultura familiar. Rio de Janeiro: Mauad, 2003. p. 135-152.

PINTO, G. M. A. De pequenino é que se torce o pepino (e o destino): um estudo sobre o trabalho infantil no meio rural. Disponível em: <http://home.utad.pt/ des/acervo_des/1996criartfpeqtor63.doc $>$. Acesso em: 7 jul. 2011.

POLTRONIÉRI, L. G. Percepção de custos e riscos provocados pelo uso de praguicidas na agricultura. In: DEL RIO, V.; OLIVEIRA, L. (Org.). Percepção ambiental: A experiência brasileira. São Carlos: EdUFSCar, 1996.

REA, L. M.; PARKER, R. A. Metodologia de pesquisa - do planejamento à execução. São Paulo: Pioneira, 2000.

SÁ, L. M. Pertencimento. In: FERRARO JÚNIOR, L. A. (Org.) Encontros e caminhos: formação de educadoras(es) ambientais e coletivos educadores. Brasília: MMA/Diretoria de Educação Ambiental, 2005. p. 245-256.

SATO, M. Biorregionalismo: a educação ambiental tecida pelas teorias biorregionais. In: FERRARO JÚNIOR, L. A. (Org.). Encontros e caminhos: formação de educadoras(es) ambientais e coletivos educadores. Brasília: MMA/Diretoria de Educação Ambiental, 2005. p. 179-189.

SOARES, W. L.; PORTO, M. F. Atividade agrícola e externalidade ambiental: uma análise a partir do uso de agrotóxicos no cerrado brasileiro. Ciênc. saúde coletiva, Rio de Janeiro, v. 12, n. 1, p. 131-143, 2007.

ZAKRZEVSKI, S. B. Por uma educação ambiental crítica e emancipatória no meio rural. Revista Brasileira de Educação Ambiental, Brasília, n. zero, p. 79-86, 2004. 